\title{
Clinical application of customized presurgical nasoalveotar molding for the treatment of unilateral complete cleft lip and alveolus: case report
}

\author{
Sridhar Premkumar ${ }^{1}$, Chellappa Roopa@Kunthavai ${ }^{1}$, Marcos Roberto Tovani-Palone ${ }^{2}$
}

\begin{abstract}
Cleft lip and/or palate $(\mathrm{CL} / \mathrm{P})$ are the most common craniofacial malformations in humans. The lip, alveolar ridge, palate and nose are areas frequently affected in people with this type of anomaly. Generally, there are also negative psychosocial impacts in children with these malformations. Moreover a son with $\mathrm{CL} / \mathrm{P}$ can become an emotional trauma to their parents. Multiple surgeries and other therapies are required for the treatment of most cases. During the first three months of life the surgical treatment of $\mathrm{CL} / \mathrm{P}$ usually involves infant orthopaedics, such as presurgical nasoalveolar molding (PNAM), primary cleft lip repair and primary rhinoplasty. PNAM is a nonsurgical method, which has been used by many craniofacial centers. However, few reports concerning the customized use of PNAM for the treatment of complete cleft lip and alveolus have been described in the literature. In addition, the treatment success through this method has been a controversial subject. In this paper, we present the case of a newborn with unilateral complete cleft lip and alveolus treated with customized PNAM, based on the experience of the Tamil Nadu Government Dental College and Hospital, Chennai, India.
\end{abstract}

Keywords: cleft lip, infant newborn, rehabilitation, esthetics, orthopedics

\section{INTRODUCTION}

Cleft lip and/or palate $(\mathrm{CL} / \mathrm{P})$ are one of the most common birth defects in humans, with a prevalence of approximately 1:700 live births. The presence of notable anatomical deformities is a characteristic finding in the vast majority of cases. The lip, alveolar ridge, palate and nose are areas frequently affected in these people $(1,2)$.

In view of that, infants with $\mathrm{CL} / \mathrm{P}$ often suffer from problems like feeding difficulties, aesthetics and speech impairments, and repeated infections of upper respiratory tract. In this context, multiple surgeries and other therapies are almost always required (1-4). As if that were not enough, such craniofacial malformations are also related to negative psychosocial impacts and can even become an emotional trauma to parents of affected sons (5). Therefore, multidisciplinary care is essential to these patients $(1,6,7)$.

In this regard, it is worth mentioning that in unilateral and bilateral clefts the facial muscles are unable to get inserted into their normal positions and hence cause displacement of the structures to which they are attached. During the first three months of life the surgical treatment of CL/P usually involves infant orthopaedics, such as presurgical nasoalveolar molding (PNAM), primary cleft lip repair and primary rhinoplasty (2).

Nasoalveolar molding, in turn, is a nonsurgical method of bringing the gum and lip together by redirecting the forces of natural growth. Furthermore, it is not painful, easy to use and, it allows for the correction of the flattened nose prior to primary surgeries and facilitates nose repair at the same time of lip repair (8). Currently, PNAM has been used by many craniofacial centers around the world (8-10). However, until now, few reports concerning the customized use of PNAM

\footnotetext{
1 Tamil Nadu Government Dental College and Hospital, Chennai, India

2 Ribeirão Preto Medical School, University of São Paulo, Ribeirão Preto, Brazil
}

Received: 23 July 2018, Accepted: 6 Aug 2018
Correspondence: Marcos Roberto Tovani-Palone

Department of Pathology and Legal Medicine Ribeirão Preto Medical School University of São Paulo 3900 Bandeirantes Ave, Ribeirão Preto, SP 14049-900, Brazil

E-mail:marcos_palone@hotmail.com

(C) 2018 by the authors; licensee Modestum Ltd., UK. This article is an open access article distributed under the terms and conditions of the Creative Commons Attribution License (http://creativecommons.org/licenses/by/4.0/). 


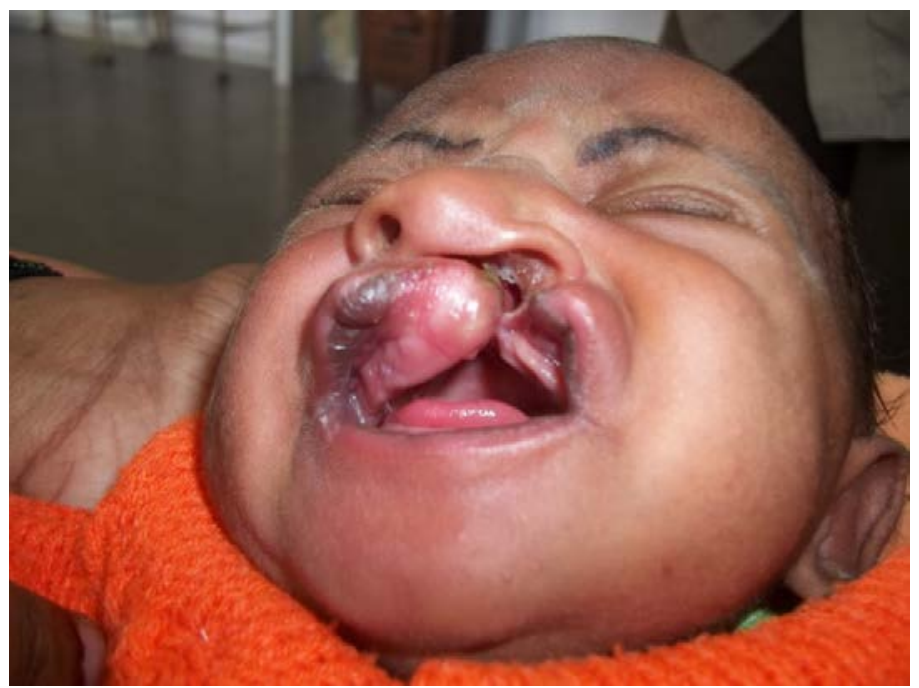

Figure 1: Neonate with unilateral complete cleft lip and alveolus. Nasal deformity, with the columella and the nasal septum inclined over the cleft area. Nasal tip was depressed and the widened nostril.

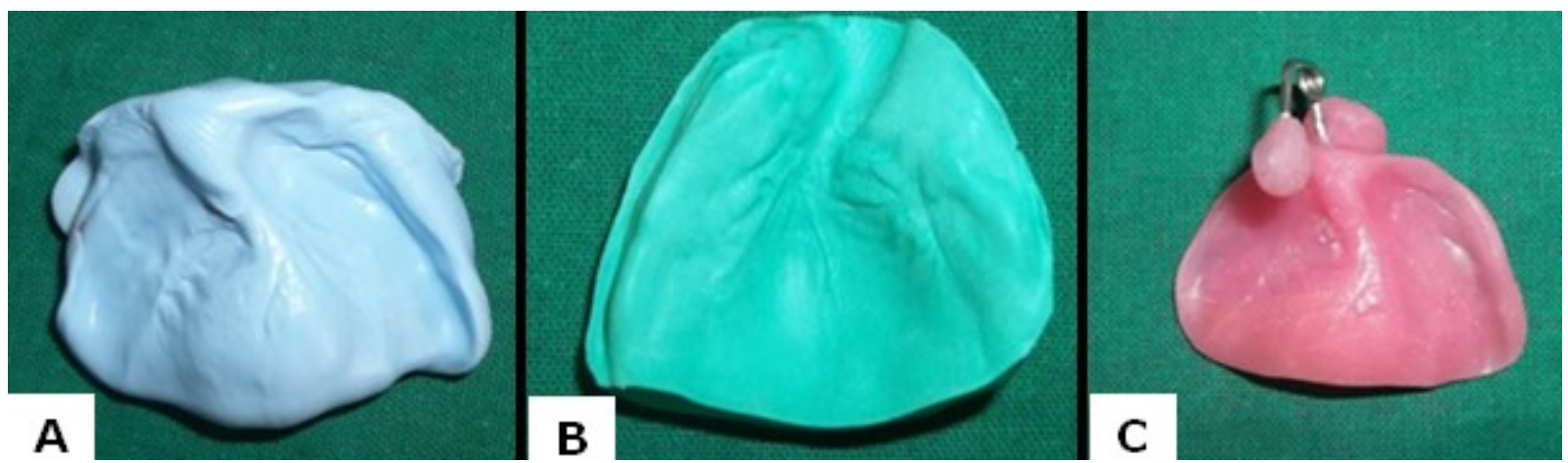

Figure 2: A) Impression with use of silicon impression material, B) Stone cast and, C) finished and polished presurgical nasoalveolar molding appliance.

for the treatment of complete cleft lip and alveolus have been described in the literature. In addition, the treatment success through this method has been a controversial subject (11).

In this paper, we present and discuss the case of a patient with unilateral complete cleft lip and alveolus treated with customized PNAM, based on the experience of the Tamil Nadu Government Dental College and Hospital, Chennai, India.

\section{CASE REPORT}

A newborn baby girl was referred to the Department of Orthodontics from the Institute of Paediatrics of the Tamil Nadu Government Dental College and Hospital, Chennai, India with the diagnosis of nonsyndromic unilateral cleft. Clinically, the patient showed a complete cleft lip and alveolus. Other observed features included the presence of severe nasal deformity characterized by nasal septum deviated towards the non-cleft side and nasal tip depressed with an evident displacement. Intraoral cleft gap was 6-7 mm (Figure 1). Initially, parents were given guidelines about how to take care of an infant with cleft, as well as concerning the treatment to be performed.

It was decided by the health team that the use of PNAM would be implemented. This was performed as described below. First, in the first week of birth, an impression was made using silicone impression material with the patient in the head upside down position. Afterwards, a stone cast was obtained. After this step, a nasoalveolar molding appliance was fabricated using auto polymerising acrylic resin. It consisted of an intraoral molding plate with a nasal stent. This stent was made with stainless steel orthodontic wire (with a design helical). Next, a nasal bulb in the shape of a ball was obtained (by addition of acrylic resin) to gradually lengthen the columella (Figures 2A-C).

In the second week of birth, the appliance was inserted and held in place with micropore tapes (placed vertically) (Figure 3A). The molding plate started to be adjusted weekly. During this period, the hard acrylic of the molding plate was selectively replaced by soft liners, in the region where we wanted the alveolar bone segments to move. With 1 month of age, micropore tapes were also placed horizontally (forming a single strap) to apply pressure in a posterior direction 


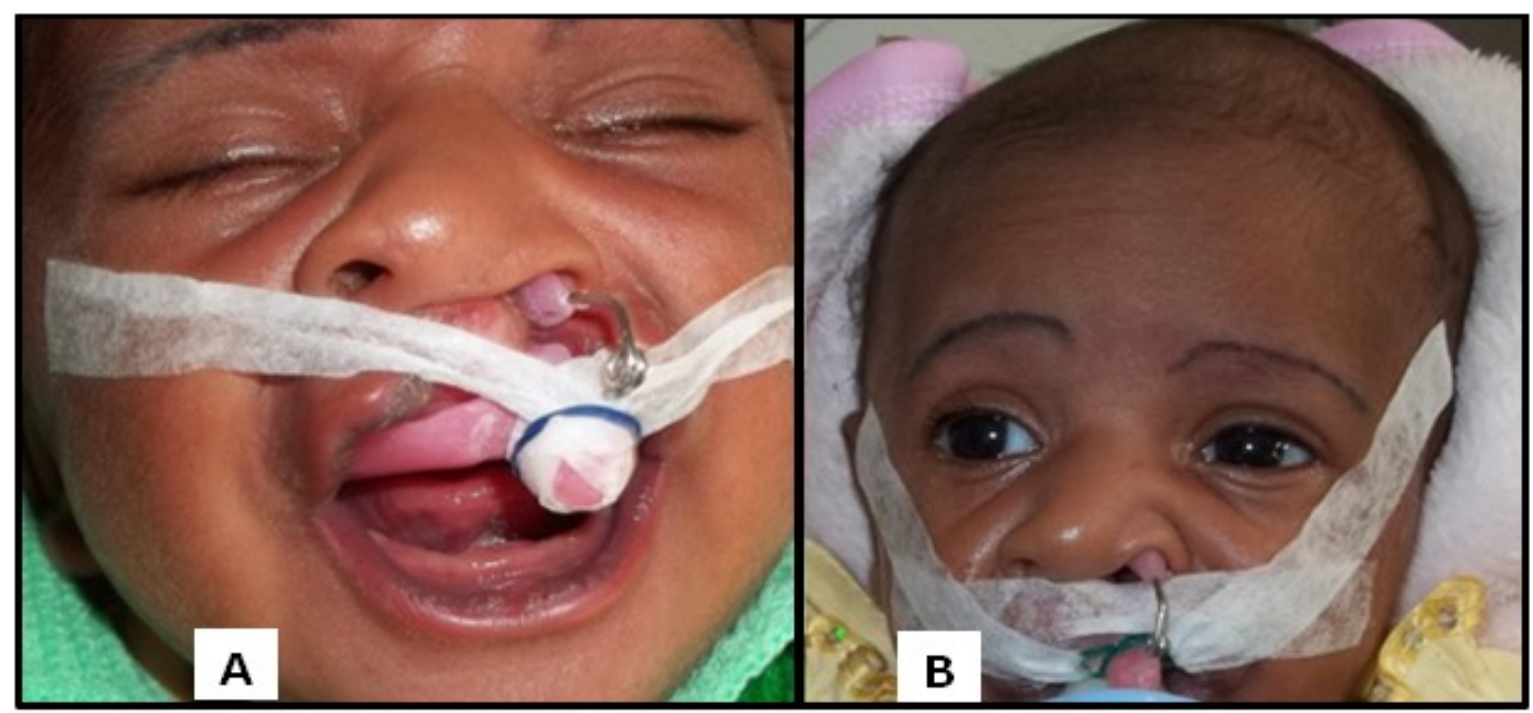

Figure 3: A) Initially the PNAM appliance was inserted along with vertical holding micropore tapes. B) With 1 month of age, horizontal tapes were also placed.

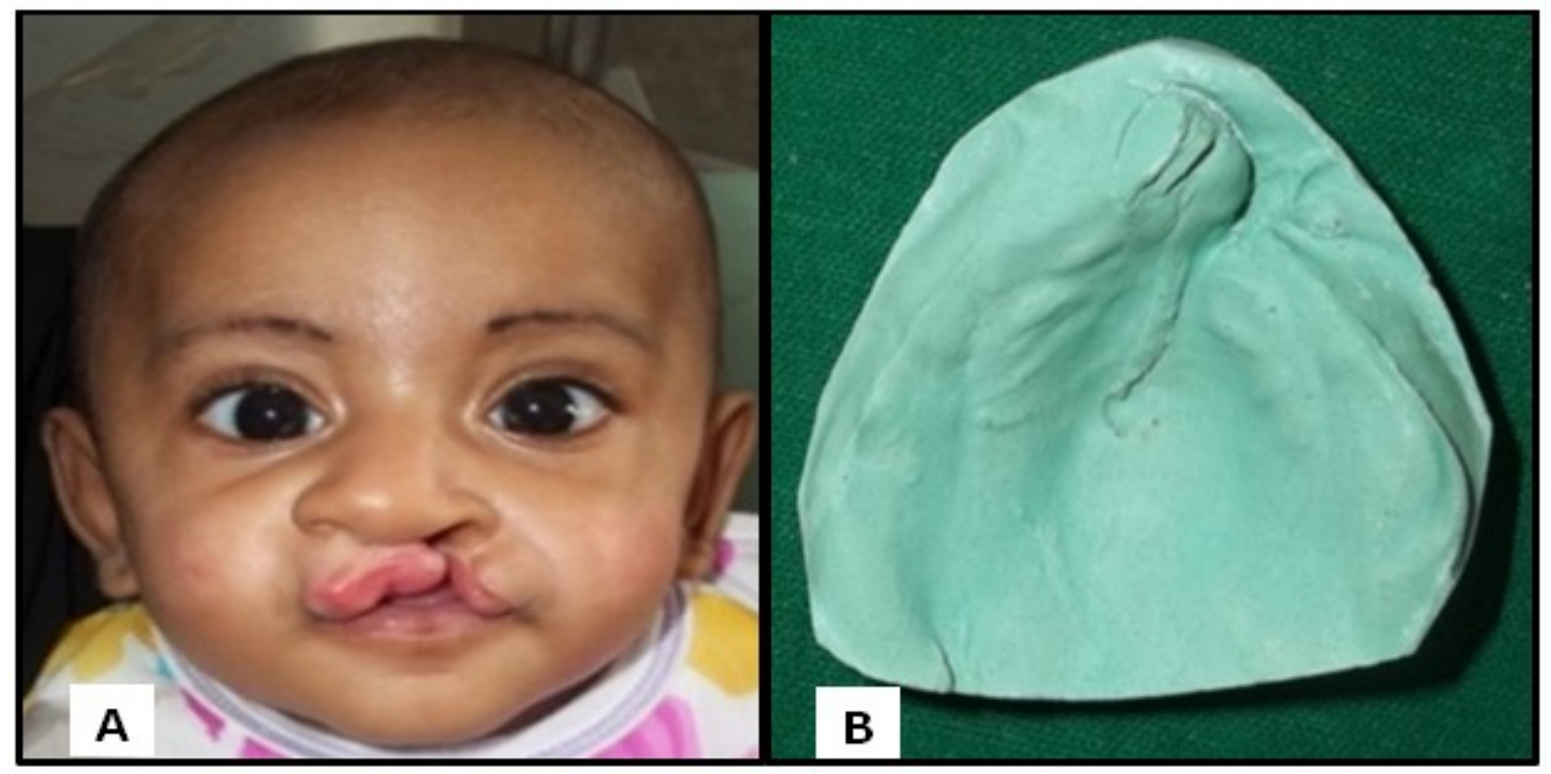

Figure 4: At the end of PNAM therapy, A) lips were approximated and columella was lengthened. B) Post PNAM model shows a reduction of the cleft gap.

on the projected maxillary and thus to approximate the lip segments (Figure 3B). In both cases, the tapes were changed by us every alternate day.

In this connection, the use of the nasal stent was very relevant, because it provided a gentle molding force to both the nasal tip and lower lateral cartilage (Figures 3A and 3B). Parents were informed about the progress of the treatment. Moreover, further counselling was given to them and other family members.

In the third month of age, with the end of PNAM, the lips of the patient were almost approximated, her nasal columella was lengthened and the nostril contour on the cleft side achieved a good outcome. In addition, the maxillary and mandibular gum pads were touching each other (passively) (Figure 4A) and an almost continuous arch form with reduced cleft gap of about $1 \mathrm{~mm}$ was observed (Figure 4B).

After PNAM therapy, the patient was referred to the Department of Plastic Surgery for surgical repair of the lip. The lip was operated with Millard's technique. Figures 5A and 5B show a continuous lip and good columella lift one month after surgery. 


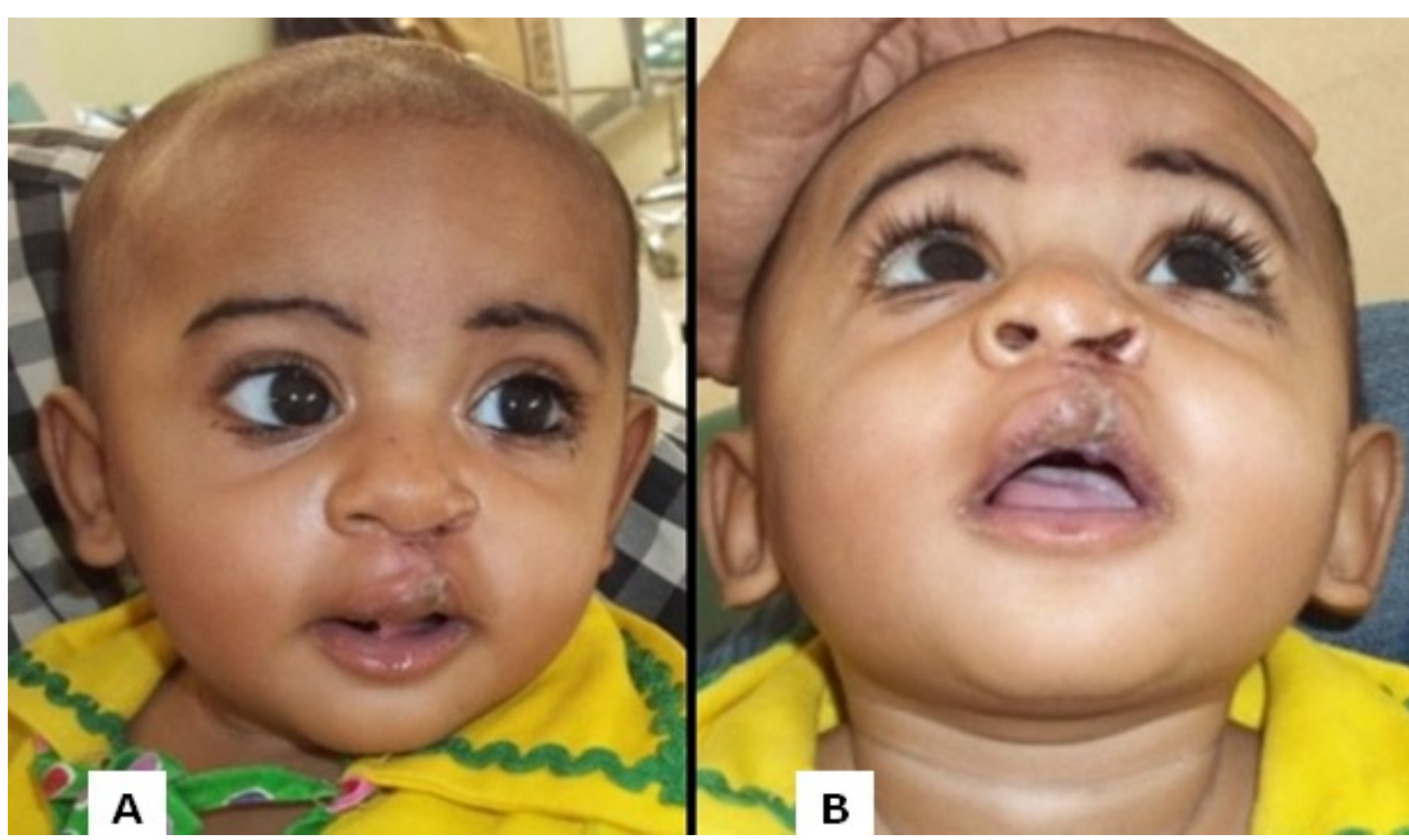

Figure 5: $A$ and B) Post-surgical extra oral photos. Good outcomes to the surgery and columella lift can be appreciated.

\section{DISCUSSION}

At present, orthodontics is a field of dentistry which can provide physical wellbeing, as well as emotional wellbeing by repositioning teeth and jaws of individuals with malocclusions for aesthetic or functional reasons.

The rationale to the use of PNAM is based on the presence of high levels of hyaluronic acid in the neonatal period. Consequently, the presence of hyaluronic acid in abundance, which is a component of the cartilaginous tissue, contributes to a good flexibility of this tissue. Therefore, in the early neonatal period, alar cartilage exhibits the same elasticity as auricular cartilage, in a way that congenital alar deformities can be treated non-surgically. However, as the infant grows older the flexibility of the cartilage decreases $(12,13)$.

PNAM is a method that has shown effective to reduce the severity of the initial cleft deformity (10). This corroborates the presented case report. With the use of this method the cleft lip segments are approximated, which produces less tension in the facial tissues before and after lip repair and reduces scars (14). Furthermore, the presurgical reduction of the alveolar cleft gap related to the PNAM therapy can result in formation of an osseous bridge, which facilitates the performance of gingivoperiosteoplasty (9). This is because there is a selective grinding of the acrylic of the appliance from the region into which one desires the alveolar bone segments to move (12).

In addition, the use of presurgical infant orthopaedics with a nasal stent during early in life contributes to the improvement of the nasal morphology (9). PNAM may promote lengthening of the columella and to make it possible to achieve a satisfactory outcome to the contour of the nostril on the cleft side $(9,10)$.

According to the present case report, the used customized PNAM method is a simple and low-cost therapy, which can minimize the need for surgical columellar reconstruction (9), with similar outcomes to more sophisticated PNAM treatments (15) and even better than others (16). Therefore, with its application a lower amount of dissection of the cartilaginous tissue may be necessary. In this regard, better outcomes for reduction of scars and relapses are also expected as advantages (9).

Another relevant point is that significant improvements in the facial aesthetics of the patient could be verified. The customized application of straps (with micropore tapes) may have been essential for the treatment success.

Other PNAM benefits include a probable reduction in the number of future surgeries such as alveolar bone grafting and secondary rhinoplasties (17). Moreover, it is expected a better cost-effectiveness potential with the use of this method in comparison to the treatment protocols without nasoalveolar molding (18).

It should also be taken into account that the treatment of infants with CL/P involves in most cases the achievements of several high complexity procedures and customization according to the needs of each patient always aiming to achieve the best possible outcomes. This may be a reality with the application of customized PNAM, which should also contribute to a better psychological health status of parents of these children (14). 
In this sense, an adequate preparation of parents for the care needs of infants with any congenital malformation (including $\mathrm{CL} / \mathrm{P}$ ) is equally important as the treatment offered to such children. The transmission of information about the correct use of the appliance is undoubtedly very relevant to the treatment successful with PNAM and absence of complications such as irritation to the oral mucosa, gingival tissue or nasal mucosa (19).

\section{FINAL CONSIDERATION}

Customized PNAM produces good outcomes to the treatment of complete cleft lip and alveolus as shown in this case report. This simple and cheap method contributes to align and approximate the alveolus and lip, and to improve the nasal symmetry. Its use can reduce the number of surgical revisions, with benefits for both the patient and the surgeon.

\section{REFERENCES}

1. Vlahovic AM, Haxhija EQ. Cleft Lip and Palate. In: Pediatric and Adolescent Plastic Surgery for the Clinician. Springer, Cham. 2017;67-87. https://doi.org/10.1007/978-3-319-56004-5_7

2. Sridhar P. Textbook of Orthodontics. 1st ed. Reed Elsevier India Pvt Ltd. 2015.

3. Tovani-Palone MR, Beja GBSP, Perez-Faverani L, Ramalho-Ferreira G. Expansão rápida da maxila assistida cirurgicamente no tratamento reabilitador das fissuras bilaterais completas de lábio e palato: particularidades técnicas. Rev Fac Med. 2017;65(1):157-60. https://doi.org/10.15446/revfacmed.v65n1.54756

4. Palone MRT, Silva TR, Dalben GS. A Bioengenharia tecidual em favor da reabilitação de indivíduos com fissura labiopalatina. Medicina (Ribeirão Preto). 2015;48(2):113-8. https://doi.org/10.11606/issn.2176-7262.v48i2p113118

5. Al-Namankany A, Alhubaishi A. Effects of cleft lip and palate on children's psychological health: A systematic review. Journal of Taibah University Medical Sciences. 2018. In press. https://doi.org/10.1016/j.jtumed. 2018.04.007

6. Tovani-Palone MR. Treatment of Nonsyndromic Cleft Lip and/or Palate in Brazil: Existing Consensus and Legislation, Scope of the Unified Health System, Inconsistencies and Future Perspectives. World Health Popul. 2018; 17(4). https://doi.org/10.12927/whp.2018.25443 Epub ahead of print.

7. Tovani-Palone MR, Formenton A, Bertolini SR. Are there regionalisation of high complexity surgeries and decentralisation of outpatient treatment services for cleft lip and/or palate in the state of São Paulo, Brazil: HK J Paediatr (New Series). 2018;23(3):211-9.

8. Singh K, Kumar D, Singh K, Singh J. Positive outcomes of naso alveolar moulding in bilateral cleft lip and palate patient. Natl J Maxillofac Surg. 2013;4(1):123-4. https://doi.org/10.4103/0975-5950.117813 PMid:24163571 PMCid:PMC3800377

9. Kinouchi N, Horiuchi S, Yasue A, et al. Effectiveness of presurgical nasoalveolar molding therapy on unilateral cleft lip nasal deformity. Saudi Med J. 2018;39(2):169-78. https://doi.org/10.15537/smj.2018.2.21020 PMid:29436566 PMCid:PMC5885094

10. Fuchigami $T$, Kimura $N$, Kibe $T$, et al. Effects of pre-surgical nasoalveolar moulding on maxillary arch and nasal form in unilateral cleft lip and palate before lip surgery. Orthod Craniofac Res. 2017;20:209-15. https://doi.org/10.1111/ocr.12199 PMid:28921849

11. Smith DM, Macisaac ZM, Losee JE. Discussion: Limited evidence for the effect of presurgical nasoalveolar molding in unilateral cleft on nasal symmetry: a call for unified research. Plast Reconstr Surg. 2013;131(1):72e-74e. https://doi.org/10.1097/PRS.0b013e3182729f80 PMid:23271556

12. Grayson $B H$, Santiago $P E$, Brecht $L E$, Cutting CB. Presurgical nasoalveolar molding in infants with cleft lip and palate. Cleft Palate Craniofac J. 1999;36:486-98. https://doi.org/10.1597/1545-1569_1999_036_0486_ pnmiiw_2.3.co_2

13. Matsuo K, Hirose T, Otagiri T, Norose N. Repair of cleft lip with nonsurgical correction of nasal deformity in the early neonatal period. Plast Reconstr Surg. 1989;83:25-31. https://doi.org/10.1097/00006534-198901000-00006 PMid:2909076

14. Thabitha Rani S, Manjula M, Sreelakshmi N, Rajendra Reddy E, Rajesh A. Supporting the drive to thrive in cleft lip and palate infant- a case report. J Clin Diagn Res. 2013;7(12):3102-4. 
15. Rau A, Ritschl LM, Mücke T, Wolff KD, Loeffelbein DJ. Nasoalveolar molding in cleft care--experience in 40 patients from a single centre in Germany. PLoS One. 2015;10(3):e0118103. https://doi.org/10.1371/ journal.pone.0118103 PMid:25734535 PMCid:PMC4347986

16. Subramanian CS, Prasad NK, Chitharanjan AB, Liou EJ. A modified presurgical orthopedic (nasoalveolar molding) device in the treatment of unilateral cleft lip and palate. Eur J Dent. 2016;10(3):435-8. https://doi.org/ 10.4103/1305-7456.184146 PMid:27403068 PMCid:PMC4926603

17. Mishra B, Singh AK, Zaidi J, Singh GK, Agrawal R, Kumar V. Presurgical nasoalveolar molding for correction of cleft lip nasal deformity: experience from northern India. Eplasty. 2010;10:e55. PMid:20694165 PMCid:PMC2916669

18. Patel PA, Rubin MS, Clouston S. Comparative study of early secondary nasal revisions and costs in patients with clefts treated with and without nasoalveolar molding. J Craniofac Surg. 2015;26(4):1229-33. https://doi.org/ 10.1097/SCS.0000000000001729 PMid:26080163

19. Grayson $B H$, Shetye PR. Presurgical nasoalveolar moulding treatment in cleft lip and palate patients. Indian J Plast Surg. 2009;42 Suppl:56-61. https://doi.org/10.4103/0970-0358.57188 PMid:19884682 PMCid:PMC2825057 